\title{
LOS IURATS DE MALLORCA Y SU POTESTAD NORMATIVA EN LA BAJA EDAD MEDIA*
}

\author{
Joaquín Cerdá
}

\section{RASGOS GENERALES DEL MUNICIPIO DE LA CIUDAD DE MALLORCA}

Cuando la ciudad de Mallorca fue conquistada por el rey Jaime I y sus ejércitos — en el siglo XIII, año 1229 - se apreciaba el auge de la vida ciudadana con un régimen municipal más o menos autónomo, independiente del poder señorial, y por ello se pudo decir que «Mallorca es, desde los primeros momentos de su conquista, una ciudad libre por especial privilegio real»1. Muntaner señalaba en su Crònica que era «de les forts ciutats del mon e la millor murada», y que «Quant hac presa la dita ciutat e la illa, la enriquehi ab majors franqueses e llibertats que Ciutat sia al mon²».

La ciudad de Mallorca conoció unos primeros momentos - de

* J. CERDÁ RUIZ-FunEs, «El régimen municipal de Mallorca en la Baja Edad Medias, trabajo redactado hace años y en el que inserí una parte de la investiga ción actual (inédito).

1 A. Pons, Constituciones e ordinaciones del Regne de Mallorca, t. I, pp. 5-6.

2 Texto citado por SALyA en Historia de la Ciudad de Mallorra, p. 408. 
1230 a 1249 - en los que el rey Jaime I otorgó a sus pobladores catalanes la llamada Carta de Franqueza, inspirada en las cartas de población de Lérida y Tortosa ${ }^{3}$; en dicha carta daba por establecidas la Curia y las magistraturas reales del veguer y del bayle; en los juicios intervendrían, además, unos hombres buenos, los prohombres, vecinos de la ciudad ${ }^{4}$. Por este motivo, decía Quadrado que en estos años «el poder municipal divagó en manos de estos prohombres nombrados libremente por el pueblo para cada negocio que ocurría, como aparece en la elección de diez comisionados para el derrame y recaudación de una talla en 1237, confirmada por el Infante de Portugal, dueño entonces de Mallorcax5.

En 1249, el rey de la Corona aragonesa se preocupaba, una vez más, de la organización de la isla, y le otorgó una nueva disposición en forma de «estatuto» por la que se organiza el verdadero régimen municipal de la ciutat, algunas de cuyas magistraturas llegaron más tarde a tener proyección en el gobierno de toda la isla. Desde entonces, al frente del municipio estaba la llamada Juraria, integrada por seis jurados como magistrados supremos, y unos consejeros (precedentes del Gran i General Consell) ${ }^{6}$, junto al bayle y veguer reales; otros cargos estrictamente locales fueron el mostassaf, el clavario, los oidores de cuentas, el cap de guaita, los escribanos, el abogado, el notario, etc. $?$.

A partir de ese año de 1249 , se puede hablar de un verdadero

3 Antoni Pons, Historia de Mallorca, t. II, p. 149. José M. Font Rius, «El desarrollo general del Derecho en los territorios de la Corona de Aragón (s. XII-XIV)», separata de las ponencias del VII Congreso de Historia de la Corona de Aragón. 1962. pp. 303-304.

4 Carla de Franqueza (1230) estudiada por SALVÁ en Boletín de la Sociedad Arqueológica 49. pp. 625-637. Alfonso GUILARTE, «La carta de Franqueza del Municipio de Mallorca», en Estudios en Homenaje a Pérez Serrano. Jaime SALVÁ, «Instituciones políticas y sociales otorgadas por Jaime I a Mallorca» en Historia de Mallorca, coordinada por J. Mascaró.

5 José M. QuAdrado, Forenses y ciudadanos, $2^{*}$ edición aumentada, 1895. p. 62 .

6 Román PiN̂a Homs, «El Gran i General Consell , Asamblea del Reino de Mallorca, 1977, pp. 49 ss.

7 José M. QUADRADO, Forenses..., pp. 62-63. Antoni Pons, Historia de Mallarca, t. II, p. 95. 
municipio en la ciudad, lo que después tendrían algunas villas de la isla ${ }^{8}$. Los documentos emplean para designar esta institución con personalidad jurídica distinta de las de los ciudadanos, el término universitat, o régimen universal ${ }^{9}$; fue frecuente el primero para designar al municipio en las ciudades catalanas. A este propósito, Font Rius dice: «Toda entidad o centro de población dotada de un régimen u organismo de gobierno propio era una "universitas"... y "universitas" se aplicaba ya al conjunto de población, a la comunidad local, como ente o cuerpo con personalidad pública», «La instauración de unos cargos, unos consejos, con unas atribuciones y un régimen de gobierno en las respectivas localidades, ratificó esta cualidad y condición de "universitas" poseída por el grupo de habitantes» 10 .

La Junta de la Consignación con los jurados, en texto de 1684 , en relación con la universitat mallorquina expresa:

En realidad no es otra cosa Universidad, sino los mismos hombres juntos en un cuerpo que la forman, aunque según la ficción del derecho representa la Universidad una persona muy distinta de los mismos particulares, que la componen, $\mathrm{y}$ así se distingue de ellos... y siendo la Universidad por ficción del derecho, persona representada, ni tienen alma, ni entendimiento, ni más cuerpo, que aquel político que finge la ley"1.

8 Lladó Y FerRaguT, El régimen municipal de los pueblos de Mallorca desde els. XIII, pp. 22 ss.

${ }^{9}$ Así, en la pragmática de Huc de Anglasola (1398), se cita varias veces: art. 1. «Primerament estatuhim e ordenam que daçi avant en pertostemps sien en la Ciutat e Uniuersitat de la Ylle del Regne de Mallorques...* (A. PONS, Const. I, p. 146). Regiment de Concordia (1440): $\alpha . .$. stant personalment en la casa de la Juraria de la dita Uniuersitat e Regne de Mallorques..." (A. Pons, Const. 1, p. 218)

10 José M. FONT Rıus, Origenes del régimen municipal de Cataluña, edición del AHDE, Madrid 1946, p. 412.

11 En Por la Junta de la Consignación con los Magnificos Jurados de la Universidad, Ciudad y Reino de Mallorca, 1767, p. 2. 


\section{LOS IURATS: TEXTOS E IMPORTANCIA}

De todas las instituciones locales mallorquinas, voy a centrar mi trabajo en los seis jurados que como magistrados supremos del municipio de la ciudad de Mallorca quedaron configurados en el citado documento del 7 de julio de 1249:

Quod habeant sex juratos in civitate Majoricarum qui gubernent et administrent per unum annum totam insulam, quorum unus sit miles, et vocem annuatim consiliarios quot et quos voluerint; et in festo Nativitatis, prasente et consentiente bajulo regio, cum consilio consiliariorum eligant juratos ipsis successorus, qui regi vel bajulo in illius absentia prasentati, prastent juramentum quod inseritur ad litteram; quod non recipiant salarium, nec possint excusare se $a b$ officio...12.

De dicho documento podemos sacar la conclusión de que los seis jurados elegidos anualmente son la representación auténtica de la ciudad y del reino que cuidarían del gobierno y la administración y serían defensores de los privilegios, franquezas y costumbres de la isla. Cargo anual y por elección - cuyo procedimiento varía a lo largo del tiempo- y siempre de carácter gratuito y de aceptación obligatoria $^{13}$. Posteriormente también se crearon tres o cuatro jurados en los municipios de algunas villas mallorquinas ${ }^{14}$.

Sobre los jurados, la Junta de la consignación en 1684 (tras recordar los precedentes romanos en la institución de los Decuriones) expresaba que:

Para declaración de la Universidad de que tratamos, tomando el agua desde su manantial, digo que el Serenísimo Señor Rey Don Jaime el Conquistador, después de haver libertado esta Isla de Mallorca de la tiranía de los bárbaros Mahometanos, que la señoreaban, dio facultad a sus pobladores de tener seis jurados habitadores en ella, para que gobernassen y administrassenjoda la Isla con poder de elegir todos los años... is.

12 Inserto en Quadrado, Privilegios y franquicias de Mallorca, Palma de Mallorca 1894. XVIII, fol. $21 \mathrm{v}$.

13 A. Pons, Historia de Mallorca, t. II, p. 96.

14 Lladó y FerRAGUT, obra citada, pp. 14-16.

15 Por la Junta de la Consignación..., p. 3, pár. 3. 


\section{LOS IURATS EN OTROS MUNICIPIOS (CATALANES, VALENCIANOS, ANDALUCES Y MURCIANOS)}

Estos jurados, magistrados representativos de la comunidad, a lo largo de los síglos XIII y XIV, los encontramos en diferentes municipios catalanes, valencianos, andaluces y murcianos, entre otros. Así, en Cataluña, junto a los consiliarii o paciarii encontramos los jurati (en número de dos, tres, cuatro o seis) como magistrados supremos municipales al lado de los prohombres consejeros y asambleas $^{16}$. Font Rius aprecia que en la Baja Edad Media aparecieron en diferentes municipios de Cataluña como autoridades directivas unos consules, paciarii o jurados, términos que hacen referencia a una misma institución; los iurati se fueron extendiendo por diferentes poblaciones catalanas para designar a las primeras magistraturas de las mismas ${ }^{17}$.

En el municipio de Valencia tenemos constancia de este oficio de los iurats junto a otros de carácter local. Pere Jeroni Taraçona en sus Institucions dels Furs i Privilegis les dedica un título junto a otros oficios de la ciudad. Eran seis jurados: dos caballeros y cuatro ciudadanos 18 .

En municipios andaluces y murcianos, desde fines del siglo XIII, hay constancia documental de que junto al iudex y los alcaldes o justicias se elegian anualmente unos jurados, que en los concejos de Sevilla y Murcia fueron seis y pertenecían a los tres estamentos de caballeros, ciudadanos y menestrales, y les señalaban unas atribuciones semejante a las de los iurats mallorquines ${ }^{19}$.

16 FONT RIus, Origenes..., pp. 389, 393-395.

17 Font Rius, obra citada en nota 16, pp. 397-398.

18 Pere Jeroni TARAÇONA, Institucions dels Furs i Privilegis del Regne de Valencia, Valencia, 1580. Nueva edición en 1976, p. 51, dice: «Cascun any en la vigilia de Pentecostes sien elets sis Iurats, en la forma que eleix lo Iusticia: dels quals los dos sien Cavallers, o generosos, y los quatre ciutadans...n.

19 Joaquín CERDA RUIZ-FUNES, "Hombres buenos, jurados y regidores en los municipios castellanos de la Baja Edad Media», I Symposium de Historia de la Administración, 1970, separata, pp. 13-20. 


\section{LOS IURATS MALLORQUINES: CARACTERES, SISTEMAS DE ELECCIÓN Y ATRIBUCIONES}

Estos jurados de la ciudad de Mallorca extendieron su acción de gobierno y administración por toda la isla. Pertenecían a diferentes clases o estamentos. De los seis, elegidos cada año, uno de ellos que aparecía como iurat en cap debía de ser caballero, otros dos serían ciudadanos, el cuarto y el quinto del estamento de los mercaderes, y el sexto sería de los menestrales ${ }^{20}$; es decir, estaban representados los tres grupos sociales de la comunidad ciudadana. El iurat en cap debía aconsejar e incluso ayudar al lugarteniente o gobernador de la isla, al bayle y al veguer siempre que le fuese solicitado por alguno de estos cargos reales.

Pons cita en su Historia de Mallorca que en una escritura de 1249 aparecen como los primeros jurados de la ciudad Francisco de Sant Martí, R. de Clergue, Valentín Ses Torres, Berenguer de Pinós y P.F. Ferrer (Ferrarius). Los jurados vestían unas gramalles, «piezas talares de color púrpura con vueltas de terciopelo negro ${ }^{21}$.

Una vez elegidos, los jurados visitaban al rey o a su delegado en la isla, en presencia del cual y ante prohombres prestaban juramento, en cuya fórmula se hablaba de la fidelidad y reconocimiento del señorío del rey, y de desarrollar su labor y tarea en pro de la utilidad y provecho de los vecinos de la ciudad y de toda la gente del reino ${ }^{22}$.

El sistema de elección de dichos jurados evoluciona a lo largo de la Baja Edad Media. Parece que, al principio, eran los jurados salientes los que, antes de su cese, elegían a aquéllos que iban a desempeñar este cargo en el año siguiente, elección que presidía y después aprobaba el representante real (lugarteniente, bayle, etc. ${ }^{23}$ ).

20 A. PONS, Historia de Mallorca II, p. 97.

21 A. Pons. En la citada página, dice de ellos el documento: «consulibus civitatis Majoricarum auctoritate totius civitatis et insula Majoricarum....

22 A. PONS, Historia de Mallorca II, p. 97.

23 Nota citada. 
Un nuevo privilegio de Jaime I, del 20 de agosto de 1273 , indica la «confirmatio quod possint juratos eligere 24 , elección realizada por los mallorquines o prohombres (?); y otro documento del rey Don Sancho de 1312. En disposición de Jaime II, de 1322, se accede a la petición de la universitat, en el sentido de trasladar la elección de dichos jurados del día de Navidad a la víspera25.

En 1373, Pedro IV de Aragón introdujo una reforma en este régimen de elección de los miembros del Gran i General Consell y de los seis jurados: la asamblea reducía el número de sus miembros a cien, más los seis jurados y los foráneos ${ }^{26}$. Una vez efectuada la designación de los consejeros, éstos echarían en una bolsa unas bolas de cera con los nombres de los citados miembros del Consejo, y se sacaría a suertes. Después se elegirían seis consejeros nuevos para sustituir a los que pasaron a ser jurados 27 .

El 10 de junio de 1398, Huc de Anglasola promulgó una pragmática en la que establece un nuevo sistema de elección. Justificó su facultad normativa en la autorización real que le facultaba para poder promulgar «nuevas pragmáticas sanciones»; en este caso, trataba de ordenar todo el régimen local mallorquín y en especial los jurados y el Gran y General Consejo, para conseguir una pacificación ciudadana. Dicha disposición la redactó tras aconsejarse de los oficiales reales, juristas, mercaderes, ciudadanos, notarios y otros prohombres. El nuevo sistema acude al sorteo entre los diferentes estamentos 28 .

El llamado régimen de concordia surge en 1440 y 1444, y tomó

24 Quadrado, Privil. núm. XXVII, p. 30.

25 QUADRADO, Privil. núm. LXXXIX, p. 34.

26 PINA HOMs, El Gran i General Consell, pp. 74-77.

27 Pedro IV de Aragón en 1373 justificó la reforma en el propio docurnento, e indicó que el nuevo ordenamiento lo promulga para el bien y fa paz, concordia y tranquilidad del reino, $y$ para evitar toda ocasión y materia de discusiones, pues hasta ahora jurados y miembros del Consejo recalan siempre en unas mismas familias (texto integro en A. Pons, Const. I, p. 89).

28 Lo regiment de Prachmatica de Mossen Huc de Anglasola. Esta pragmática rigió durante bastante tiempo en Mallorca como ley estatal venerada. Se denominaba por ello Santa Pragmàtica. En A. Pons, Const. 1, introducción, p. XIX; texto pp. 141-190. 
como base una carta del rey dirigida a los jurados y prohombres de la ciudad en diciembre de 1439, en la que les exponía la necesidad de dar nuevo orden al regimiento. Se denomina de concordia porque trataba de armonizar las elecciones atendiendo a la discreción de los electores y a la suerte, para evitar luchas y divergencias ${ }^{29}$. Se confeccionarán dos libros: uno en la gobernación y otro en la universidad, en los que se inscribirán los nombres de todos los hombres de Mallorca mayores de 25 años - de la ciudad y de fueraque fuesen idóneos para aconsejar a la universidad y reino en los actos de regimiento universal, a juicio del lugarteniente o gobernador y de los jurados de ciudad y reino. Cada tres años se actualizarían los dos libros. Y después, por sorteo, se procederá a la elección de consejeros y jurados.

A partir de 1447, surgió un nuevo régimen que se denominó «de sach e de sort», pues se realizaba sobre la base de unos sachs, y dentro de cada uno una serie de nombres de los que se sacaban por suerte los que habían de desempeñar los cargos de jurados. Esta elección se efectuaba por medio de cuatro sachs, correspondiendo a los diferentes estamentos a que pertenecían los iurats. Un procedimiento análogo se seguiría para la designación de los consejeros de la Asamblea ${ }^{30}$. Este régimen estuvo vigente durante casi tres siglos, con leves modificaciones, y quedó derogado por el Decreto de Nueva Planta de Felipe V, de $1715^{31}$.

POTESTAD NORMATIVA DE LOS IURATS:

LAS ORDINACIONS

Las atribuciones y limitaciones de los iurats son muy variadas. Las encuentro genéricamente expresadas bajo las palabras «qui gubernent» $\mathrm{y}$ «qui administrent», señaladas antes, que pertenecían al documento de creación de dichos magistrados. También, en el texto

29 «Regiment de Concordia», en A. Pons, Const. I, pp. 218 y 223.

30 «Regiment de Sach e de Sort», en A. Pons, Const. II, pp. 214-290.

31 QUADRAdo, Forenses..., pp. 72 ss. 
del juramento se exponen las materias que deben preocuparles, como la fidelidad al rey ${ }^{32}$ y el reconocimiento de su señorío, el desarrollo de una labor en pro de la utilidad y el provecho de todos los pobladores de la isla de Mallorca. Especificamente voy a señalar: la obligación de defender y salvar las libertades, franquezas y exenciones mallorquinas ${ }^{33}$, el poder proponer al lugarteniente general o gobernador medidas en beneficio de la ciudad o la isla ${ }^{34}$; son competentes junto a otros cargos en los problemas relacionados con el aprovisionamiento de víveres y alimentos para ciudades y villas ${ }^{35}$; tienen competencia para establecer, de acuerdo con los oficiales, nuevos estatutos o normas ${ }^{36}$; deben preocuparse de intervenir en las cuentas de los bans $^{37}$; igualmente les pertenecen las concesiones de aguas a la ciudad 38 ; los jurados tienen competencia para designar al escribano de los clavarios, y a los acequieros de la ciudad 39 ; deben intervenir dos de los jurados en las torturas ${ }^{40}$. En cambio, tienen una serie de limitaciones: no pueden participar en la administración de justicia y en ninguna otra jurisdicción ${ }^{41}$, ni hacer inquisiciones ocul-

32 «Que no fassen res en prejudici del Señor Rey e sin fant que sian compellits», en MoLL. Sumari..., p. 312.

33 A. Pons, Const. 1, introducción, p. VII.

34 Por ejemplo, en doc. de 1331, II, 16, wel lugarteniente general, a instancia de los jurados del Reino, manda a todos los patrones de naves, en donde sea que se hallen, carguen de trigo y se dirijan lo más pronto posible al puerto de la Ciudad de Mallorca». En Vich, Documentos, p. 153.

35 «Los Iurats poden fer descaragar Forments, e altres Vitualles en lo Regne, e detenir los navilis, es en libre den Sant Pera», en Molı. Sumari..., p. 312

36 «Que los lurats no poden fer statuts si primer los Officials no son requests», en Mou, Sumari..., p. 312.

37 "Que vn o dos dels Iurats entrevenguen en los comptes dels bans», en Mole, Sumari..., p. 312.

38 «Las concessions de les aygues de la Ciutat de Mallorques pertanyen als Magnifichs Iurats», en MoLL, Sumari..., p. 313.

39 «Los Iurats ban a donar lo Officci de stos sequier de la Ciutat», en MoLL, Sumari..., p. 315.

40 «Que dos dels Iurats entrevenguen en les Turtures», en MOLL, Sumari..., p. 313.

41 «Los Iurats no poden haver Jurisdictio ludiciario ni arbitraria», en MoLL. Sumari..., p. 312. 
$\operatorname{tas}^{42}$; no pueden imponer colectas sin permiso del rey o de su lugarteniente ${ }^{43}$. Los jurados pueden elevar al rey peticiones que no puede impedir el gobernador 44 . He aquí, y no de forma total, atribuciones y limitaciones que configuran la importancia de estos magistrados en el gobierno de la ciudad y reino de Mallorca.

Pero la potestad que considero fundamental es la que se refiere a la participación de los iurats en la formación del derecho mallorquín. Conocemos como el sistema jurídico de las islas ${ }^{45}$ estaba integrado por la costumbre, reconocida en los primeros privilegios reales y que adquirió posteriormente importancia; la legislación real, y las ordinacions, que eran una actividad legislativa emanada de los iurats con el consenso del Gran i General Consell, sancionada y promulgada por el rey o su representante en la isla ${ }^{46}$. De otra parte queda el derecho supletorio.

Las ordinacions vienen a llenar la falta de una actividad legislativa de las Cortes de otros reinos, que no aparecen en éste. Surgen a partir del siglo XIV, por iniciativa de los iurats de la ciudad y reino, autores de los proyectos que, tras la aprobación de la Asamblea, fueron sancionados y promulgados por el gobernador o virrey. Para Antoni Pons, «son las disposiciones dictadas por los jurados, con el asenso del Grande y General Consejo, aprobadas y mandadas publicar por el gobernador, con lo cual adquirían fuerza de ley ${ }^{47}$. Igualmente por iniciativa de los jurados o a su ruego, algunos juris-

42 «Que los Iurats no poden fer Inquisicions ocultes», en MoLL, Sumari..., p. 312 .

43 «Los Iurats no poden imposar collectes sens licencia del Señor Rey o de son Llochtinent», en MoL.. Sumari..., p. 314.

44 «Si los Iurats tremeten al Señor Rey Nunsios lo Governador no impedesca aquells», en MoLL, Sumari..., p. 314.

45 Luis Pascual González, Derecho Civil de Mallorca. Luis Pascual GONZÁLEZ, «Bosquejo histórico y estado actual de las fuentes del Derecho Foral de Mallorca», RDPriv. 217, 1931, pp. 289-294. Font Rrus, «El desarrollo general del Derecho...", CHCA, 1962, pp. 302-306 y 318-321. Encarna RoCA, "El sistema de fuentes del Derecho de Mallorca», ADC 35/1, 1962.

46 A. MOLL, Sumari... pp. 313, 314 y 315. PIN̂A HoMs, op. cit., pp. $89-90$ y 96.

47 A. Pons, Const. I, intr., p. XX. J. CERDÁ RuIz-FunEs, «Ordinacions de Mallorcan, NEJSeix (en prensa). 
tas o notarios procedieron a la recopilación de estos diferentes textos jurídicos. Por un privilegio del rey Sancho de Mallorca de 1316, reiterado en 1322, y ratificado por Juan I en $1390^{48}$, «Los Iurats poden fer ordinacions ab authoritat, e decret del senor Lochtinent, es en Libre den Sant Pera, en cartes 165, en la segona pagina, comensa Nos Loannes ${ }^{49}$. Las ordinacions no se podían contracedir ni apelar, conforme consta en documentos de la época ${ }^{50}$.

Si observamos la estructura de las ordinacions, podemos apreciar como se inician; unas veces, con la crida, especie de pregón o bando donde, tras los nombres del gobernador que sanciona y los de los jurados que la proponen, se insiere una breve síntesis de su contenido; en otras, comienza con un texto semejante a la crida, aunque no lleve esa denominación. Siempre el primer nombre que se insiere es el del gobernador o virrey con todos sus títulos. Excepcionalmente, es el propio monarca quien la sanciona y promulga; con dicho acto, el texto adquiere fuerza de ley. Así se dice, por ejemplo, en las Ordinationes de Mossen Pelay Vniz, que fueron redactadas por los jurados con el consejo de Misser Iuan Berad saui en dret, y de otros juristas y prohombres notables, siendo presentadas al honorable regente del reino, por quien, tras examinarlas, fueron autorizadas y aprobadas ${ }^{51}$.

El contenido es muy variado, está dividido en párrafos o capítulos a veces numerados, en ocasiones son textos extensos. Los temas que regulan tienden siempre a resolver problemas o necesidades de la comunidad o de su gobierno. En otros documentos se recuerda a los monarcas y gobernadores la vigencia de los privilegios, franquezas y ordenaciones de Mallorca frente a nuevas disposiciones reales contrarias, en cuyo caso se declaran estas últimas nulas, sin valor, y no debían ser obedecidas. Hay, además, otras que se refieren a temas judíciales y de carácter procesal, pues la recta

${ }^{48}$ Font Rius, Ponencia CHCA, 1962, p. 320.

49 A. MolL, Sumari,.., p. 313.

50 \&egu nos puga appellar ni puga contradir a les Ordinacions fetes per los lurats de ab concell de promens empero que sien autorizades per lo Governadors, en MoLL, Sumari..., p. 315.

51 MoL., Ordinacions y Sumari..., pp. 1-2. 
administración de justicia preocupó siempre a los jurados en los siglos XIV, XV y XVI. Tratan de jueces y tribunales, de posibles instancias y apelaciones, de la necesidad de acortar los plazos en diversas fases del proceso o la de no recurrir a la práctica del tormento sin juicio. Es decir, tendían al «buen gobierno y ejercicio de la justicia, necesidad y utilidad del reino de Mallorca» ${ }^{52}$.

Otro tipo de ordinacions está representado por una colección de Stili sive ritus curiarum. El 30 de julio de 1344, el gobernador Arnal Erill sancionó y dio orden de publicación de unas ordinacions que versaban sobre usos y prácticas de la justicia. Este gobernador, tras deliberaciones con los jurados de la universidad, y con su consejo, ordenó «quod consuetudines e stili qua in Curiis nunc obseruantur, redigantur in scriptis de catero in Curiis...». Se trataba de unas costumbres que llegaron a ser «estilos» (observancias) en la Curia judicial, y que se fijaron por escrito en esta colección ${ }^{53}$. Su contenido, según Font Rius, «adicionado por los gobernadores que sucedieron a Erill, afectaba a la vida jurídica procesal y a la práctica notarial... e indirectamente a algunos aspectos del derecho de familia y sucesorio ${ }^{54}$.

Las ordinacions quizá en sus orígenes presentaron carácter local, pero pronto tuvieron aplicación general en el reino. Es lo mismo que ocurrió con los jurados y asambleas, que su acción de gobierno y administración se extendió por toda la isla.

Los mismos iurats desde el siglo XIV instaron a notarios o juristas mallorquines a llevar a cabo recopilaciones de privilegios $y$ pragmáticas reales, uniéndose en algunas las ordinacions. Estas recopilaciones son la mayoría de caracter cronológico, y reúnen por separado los distintos materiales recopilados. Sólo entre las más importantes destacamos dos: la de Rosello sobre el Libre de Sant Pere (s. XIV), y la de Canet y Mesquida (s. XVII). Para una síntesis de las recopilaciones más importantes, pueden ser utilizados el Manual de HDE (tomo I) de García-Gallo, y la Legislación y jurisprudencia en la España del antiguo régimen de Pérez Martín y Scholz.

52 Mot. ., Ordinacions y Sumari..., pp. 43 ss.

53 MoL.L, Ordinacions y Sumari..., pp. 121 ss.

54 Font RiUs, Ponencia CHCA, 1962, p. 320. 
En el año 1863 se llevó a cabo una recopilación por el notario Antoni Moll, a ruego de los jurados de la ciudad y reino, titulada Ordinacions y sumari dels privilegis, consvetvds, y bons vsos del Regne de Mallorca.

En 1894-1896, Quadrado publicó una colección bajo el título de Privilegios y franquicias de Mallorca, cédulas, estatutos, órdenes, y pragmáticas otorgadas por los reyes de Mallorca, Aragón y España (s, XIII-XVII).

En 1934, Antoni Pons publicó Constituciones e ordinaciones del Regne de Mallorca (s. XIII-XV). 